\title{
Cost-Effective Electric Energy Bidding Strategies Applying with Particles Swarm Optimization and Adaptive Particle Swarm Optimization
}

\author{
Pramesh Kumar, S.K. Bharadwaj
}

\begin{abstract}
Electric energy market is to increase their profit for electricity providers (generators) in an open competitive electricity market and reduce reduced consumer costs by taking into account available power supply, power demand, market clearing prices (MCP) and constraints. The main contribution of this paper is provided more benefit for supplier and this new technique has used overcome the problem of electricity bidding. It may be highly important to manage the market of electricity as per the fair rules. In this paper, PSO and APSO are used to solve the bidding problem. PSO and APSO have many characteristics that similar to Genetic Algorithm (GA) evolutionary computational strategies. Firstly, by integrating the random solution and updating the generation, we get optimal results in the problem space. The possible solutions known as particles are flowing in every direction through the problem area in the PSO, following the optimal current (particle) solution. APSO is recommended for enhancing PSO efficiency (i.e. a different weight modification technique in APSO, weight varies according to the particle size). In the proposed method we use one numerical with six generators (GENCOs) and two large consumers (DISCOMs) are taken into consideration in which total profit is better than in APSO as compared to PSO.

Keywords- Bidding Strategy, Competitive Electricity Market,
\end{abstract} MCP, PSO \& APSO

\section{INTRODUCTION}

The electric energy market around entire world have moved from regulated market to restructuring market structure and public utilities have been privatized. By shifting the traditional supply of power towards a competitive energy market, the deregulation has significantly increased the world's count [1]. As a result, GENCOs considered improving their generating capabilities on different markets in order to maximize profit in a deregulated environment [2]. In recent years, the Indian electricity market changed significantly. This is primarily because of three factors: attractive prices, bilateral trade growth and the implementation of power exchanges [3].

Revised Manuscript Received on April 04, 2020.

* Correspondence Author

Pramesh Kumar*, Research Scholar, Maulana Azad National Institute of Technology Bhopal M.P. India.

Dr. S. K. Bharadwaj, Professor, Electrical Engineering Department MANIT Bhopal M.P., India.

(c) The Authors. Published by Blue Eyes Intelligence Engineering and Sciences Publication (BEIESP). This is an open access article under the CC BY-NC-ND license (http://creativecommons.org/licenses/by-nc-nd/4.0/)
The large consumer (customers) and generators (providers) begin interaction with the power transaction after the process of deregulation, and maintain system security via independent capable system operators (ISO) [4]. Several producers, transmission companies, distribution companies and network operators are struggle power market difficulties [5].The main entity of reforming the electricity market is abolish for old generation and profitable policies. This ensures that the electricity market will be competitive at all rates [6]. This reform establishing competitive contracts for trade, the price-demand ratio and so on raises many questions on the open power markets for instance the mistreat of energy market, revenue-tilting characteristic of the market. Based on theoretical knowledge, a generator (supplier) tends to bid for profit at its costs of production in an entirely competitive electrical market [7]. But the generator (GENCOs) wants to make a profit, in practice due to the profit oriented nature of the electricity market, they offer at higher prices than market position clearing price (MCP) [8] .The bidding problem begins now, as generators (providers) have to deal with the challenge (i.e. finding the optimal bidding condition, as their production costs, technological requirements, and other bidder and electricity market behaviours) [9]. This problem in the electric energy market is regarded like a strategic bid concern. There are many approaches to resolving this issue, but three solutions have mostly been published in various journals, primarily through the estimation of MCP, secondly, the approach to game theory and thirdly, the rival's approach is evaluated to bidding [10]. This paper focuses on latest techniques for biding strategy for companies and large consumers namely Adaptive Particles Swarm Optimization (APSO) and similar to Particles Swarm Optimization (PSO) [11].The result obtained by APSO is enhanced than result of PSO and this is a profitableness optimization system and can provide better solution in a short period of time.

\section{NEED OF A BIDDING MODEL}

The monopoly is removed in generating sector subsequent to restructuring the electricity market. In this way, power providers and power consumers are free to buy and sell power from anywhere [12]. Such systems which transmit the power between the power provider and the power consumer are known as bidding of power system [13]. Throughout many countries there is an electricity market in which such transactions take place. The power provider and consumer should have a bidding model, differ according to previous bidding experience [14] bidding competitor behaviours, etc.

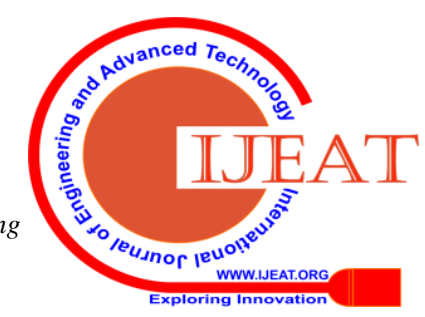


In India, IEXs (Indian Energies Exchange) performs these transaction between participators for bidding in the energy exchange. The bidding problem is regarded as an optimization topic in this article. In this article the problem of bidding has been solved by a suitable optimization bidding technique. Generators (GENCOs.) and large customer (DISCOMs.) wants boost their profit in the competitive electricity market [15]. Completes the bidding process by taking an acceptable bidding model whereas considering the bidding actions of rivals (competitors) behaviours to increase their benefit [16].

\section{CATEGORIZATION OF BIDDING}

Four types of electric energy bidding strategies are mainly found in various countries of world. .The explanatory descriptions of all are given below which are as follows:

\section{A. Single-Part Bidding}

Generators (suppliers) bid on this kind of bidding only at hours for individual rates, and this kind of market clearing process is carried out because the winner is decided by the cross-section position of the power providing curves and power demanding bid curve scheduled for each hour. As with the multi-part deal, this approach is not centralized. This category of deal is therefore completely decentralized. The unit commitment is not made by the market participant in this situation [17]. Generators (providers) must therefore take all the costs involved and substantial outer limits into account within construct own trade bids. While the total cost is not guaranteed in this form of bidding structure. These bids therefore do not undertaking capability. Unactivated electrical markets like Australia, California, or Norway and Sweden have been able to make a single-part power trading.

\section{B. Multi-part Bidding}

A multi-part transaction is also called a complex power trading scheme. The price of the ramping, set up price, downtime prices, unloading operations, in addition to the electricity prices may be separate. This form of trading can be considered the ideal one, since it demonstrates the correct cost structure and technological generator (supplier) parameter limits [18]. The market clearing procedure is based on a methodology for optimization of the remuneration tradable power. All bidders have to provide the relevant data and optimum decision is taken by the market regulator. In this form of bidding, technological feasibility is assured. The British Wales electricity market is a very famous example of the multi-part contract.

\section{Iterative Bidding}

Bidding generators (GENCOs) and large consumers (DISCOMs buyers) can adjust or change their bids under certain conditions like this [19].Although cost and technical constants are included in power trading. In some cases this method of trading is not very suitable. At all iteration, sending the generator gradient to ISO at a fixed price and cost function and values are adjusted in such a way that social benefit maximum achieves[20]. A significant difference in this method with the knowledge of ISO that we do not need a generator to sharegradients. There is a relationship between these iterative processes working to encourage generators (suppliers) for alter or adjust their bid one more time for anticipation of obtain generation requirements in the initial around of market clearing. Based on this bids scheme, the optimum biding problem is solved and the neural network is utilize for this purpose on a radial basis.

\section{Demand Side Bidding}

In demand side trading, the consumer plays an active role in trading by changing the way of own bidding pattern. At the time of bid process, all producers and large (buyers) customers are bidding to maximize social welfare. The customer should present the bid and be ready to pay it. The entire bid is picked by the winning bidder [21]. Privacy of the bidding process is taken care also buyers will no longer remain passive.

\section{PRICING METHODS}

The continuation of electric marketing and finances of extent, different pricing methods have planned for poolbased market as

-Uniform pricing (UP) clearing method and

-Pay as bid (PAB) pricing method.

Under uniform pricing method accepted participants are paid with MCP value, whereas under pay as bid method participants are paid as per their bid price. Although the uniform pricing (UP) method has numerous advantages superior than the pay as bid (PAB), it is mostly decided that $\mathrm{PAB}$ is fewer subjected to connivance and strategic provide reduction [22]. Nowadays pay as bid (PAB) pricing regulation is projected to trade the uniform pricing (UP) regulation within the reorganized power markets, through the prospect that it have insignificant market prices and condense incriminate volatility.

\section{BIDDING SCENARIO IN INDIA}

Two power exchange work effectively in India are follows as

\section{A. Power Exchange (PX) of India Ltd (PXIL)}

Power Exchange was established in 2008 by Indian government for power producers and power consumers to buy or sell at reasonable prices. It was established under the direction of the Electricity Act (EA) 2003, whichever is the primary legislation enforced by means of rules and regulations on fair promotion on the electrical energy market principle of non-discriminatory free access to power. While the main steps taken by the Electricity Act, substantial progress was experienced by the country's power markets in 2003 [23]. Encouraging regulatory efforts to create a competitive market and help market operator efforts to bring new products and services to customer, manufacturer and power sectors as a whole are encouraging.. Under Day ahead spot (DAS) market, bidder can trade for liberation of electrical energy for the 24 hours of the next day [24]. Associates can bidding for per capita hourly transaction or for block of hourly transaction at the same time as suitable. PXIL taken permission from CERC to trade in weekly market since August 31, 2009. Under weekly market, persons can trade for liberation of electrical energy for the complete delivery week which is from monday to sunday now.

Published By:

Blue Eyes Intelligence Engineering \& Sciences Publication 
In Indian prospects, an unconventional approach was used before power exchanges operation for short-term purchases of electricity, which consists unscheduled power exchange (UI) marketplace (wherever charge be unstable) and the trading processes over the counter (OTC) (typically costing transactional services). Only with OTC systems, previous customers needed a forum to allow them to enter into uniform agreements and take care of the counterpart risk. The consumer (DISCOMs) demand for such agreements contributed to the establishment of the Indian electricity exchange. Currently, India's power exchange accounts for $30 \%$ of the short-term energy trade, thereby providing a valuable bridge to resolve the power demand gap.

\section{B. Indian Energy Exchange (IEX)}

IEX is the first power exchange in India. It has been modeling ,based on the international power exchange, Nordpool [25]. It serves as an optional, electronic, nationwide platform for trading for electricity. It is developed by trade and industry knowledge (India) Ltd and PTC India economic Service inadequate. It have two sub-markets. They are as following

1. Day Ahead market (DAM) and

2. Term Ahead Market (TAM).

DAM offers 24 separate hourly products. Price discovery in DAM is through double side bidding and suppliers and buyers receive/pay uniform price [26]. Currently it works on 15 minutes scheduling rather than hourly day ahead scheduling. TAM offers other products like week ahead, year ahead and seasonal contracts. Time line of the IEX is set in agreement with the operations of regional load dispatch centers. IEX coordinates with the NLDC/RLDC and SLDC for scheduling of traded contracts to get up to date network conditions. The exchange has 29 state utilities, 110 Private generators and 145 direct consumers participating for better managing their energy portfolio. The highlights of the proposed day ahead market operation of IEX are as follows. First it will collect the existing convey capability on all inter regional links from RLDC's. Then it will receive bids and offers from potential buyers and sellers during the bid call period [27]. The bids and offers will be processed to determine the MCP and MCV. An effective agenda is given by the power exchange to the NLDC. The NLDC sending the agenda to particular RLDC's and SLDC. SLDC delivered the agenda to concerned buyers (DISCOMs) or generators (GENCOs). it is schedule that power has been delivered.

\section{PROBLEM FORMULATION}

Mathematical modeled problem are taken in order to understand the real nature of electricity bidding environment subsist describe here. Assuming a power producer (GENCOs) comprise of " $M$ " no. power GENCOs (suppliers) and an interconnected arrangement operated in the electrical energy market by an independent (separate) system operator(operating power) (ISO). Power consumers have been occupied by " $N$ " consumer (DICOMs) to balance the electricity price by demand (consumer) side bidding. A PX determines of these spectrum of GENCOs (suppliers) with main consumers (purchasers). The contract is carried out as a linear non-declining supply feature given to generators (suppliers) and extensive customer (buyers). Linear supply curve for generators in bidding are indicated.
A method to solve more complex contamination is given below.

$\mathrm{R}=$ The standardized market clearing power price to be calculated

$\mathrm{Q}(\mathrm{R})=$ Demonstrating the dependence of all the participants of the power exchange and the electricity price based on the load forecast of the power exchange

$$
\begin{aligned}
& a_{i}+b_{i} * P_{i}=R \quad i=1,2,3 \ldots \ldots \ldots \ldots
\end{aligned}
$$

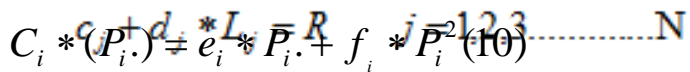

$$
\begin{aligned}
& \sum_{i=1}^{M} P_{i}=Q(R)+\sum_{j=1}^{N} L_{j} \\
& P_{i \text { IMin }} \leq P_{i} \leq P_{i \text { Max }} \quad i=1,2,3 \ldots \ldots \ldots \ldots . . m \\
& L_{j: M i t} \leq L, \leq L_{j M a x} \quad j=1,2 \ldots \ldots \ldots . . n \\
& Q(R)=Q_{0}-K * R
\end{aligned}
$$

Where, $Q_{0}=A$ natural constant numbers and

$\mathrm{K}=$ Coefficient denote the cost elasticity of the combined demand. If pool demanded is mainly inelastic, in that case $\mathrm{K}=0$.

The inequalities constraint of (4) and (5) are disregarded, the explanation to Egs. from (1) - (3) are:

$$
R=\frac{Q_{0}+\sum_{i=1}^{M} \frac{a_{i}}{b_{i}}+\sum_{j=1}^{N} c_{j}}{K+\sum_{i=1}^{M} \frac{1}{b_{i}}+\sum_{i=1}^{N} \frac{1}{d_{j}}}
$$

and $a_{i,}, b_{i}$ and $c_{j,}, d_{j}$

are non negative bidding coefficient

$$
\begin{gathered}
P_{i}=\frac{R-a_{i}}{b_{i}} \quad i=1,2,3 \ldots \ldots . . M \\
L_{j}=\frac{c_{j}-R}{b_{j}} \quad j=1,2,3 \ldots \ldots \ldots . N
\end{gathered}
$$

While the result set $(8) /(9)$ violate amount produced/customer order limits (4)/(5), it should be present customized to provide accommodation these limits.

For the power provider has the price role are given by

$$
C_{i} *\left(P_{i} .\right)=e_{i} * P_{i} \cdot+f_{i} * P_{i}^{2}(10)
$$


The profit maximize the purpose for structure and trading strategies able to be express the same as:

Maximization: $F\left(a_{i}, b_{-i}\right)=R P-C_{i}\left(P_{i}\right)$

\section{Where}

\section{$C_{i}\left(P_{i}\right)=$ Production ostfunction of the $i^{\text {th }}$ supplier.}

This is to determine $a_{i}$ and $b_{i}$ therefore like to exploit subjected to these constraints (1) - -(5).

In the same way, for the $j^{\text {th }}$ large consumerhas revenue function

$$
B_{j}\left(L_{j}\right)=g_{j} * L_{j}-h_{j} * L_{j}{ }^{2}
$$

The profit maximize intention in favor of structure a bidding strategies able to be describe as:

Maximizati on: $B\left(c_{j}, d_{j}\right)=B_{j}\left(L_{j}\right)-R \cdot L_{j}$.

This is to determine $c_{j}$ and $d j$ so as to maximize subject to the constraints (1) - (5).

$B_{j} L_{j}=$ The demand (benefit) function of the $j^{\text {th }}$

large consumer.

Within the sealed bidding transaction have base power trading facts in favor and then bidding phase is classified, in addition to therefore power providers large (DISCOMs) consumers perform not include the consecutively desirable to resolve the optimization difficulties of the system (10)/(11).

Assume that the power provider's position analysis, of rival's (j) trading coefficients and observe a cooperative nomal distribution by way of the subsequent probabilities density function (PDF):

$$
\begin{aligned}
& \operatorname{pdf}\left(a_{(j)} b_{(j)}\right)=\frac{1}{2 \prod\left(\sigma_{(j)}{ }^{(s)} \sigma_{(j)}{ }^{(b)}\right) \sqrt{\left(1-\sigma_{(j)}{ }^{2}\right)}} \\
& \times \exp \left\{\frac { 1 } { 2 ( 1 - \sigma _ { ( j ) } { } ^ { 2 } ) } \left[\left(\frac{a_{(j)}-\mu_{(j)}{ }^{(s)}}{\sigma_{(j)}{ }^{(j)}}\right)-\right.\right. \\
& \left.\left.\frac{2 \sigma_{(j)}\left(a_{(j)}-\mu_{(j)}{ }^{(s)}\right)\left(b_{(j)}-\mu_{(j)}{ }^{(b)}\right)}{\left(\sigma_{(j)}{ }^{(s)} \sigma_{(j)}{ }^{(b)}\right)}+\left(\frac{\left(b_{(j)}-\mu_{(j)}{ }^{(b)}\right)}{\sigma_{(j)}{ }^{(b)}}\right)\right]\right\}
\end{aligned}
$$

$\sigma_{(j)}=$ Correlatio $\mathrm{n}$ coefficien $\mathrm{t}$ between $a_{(j)}$ and $b_{(j)}$ $\mu_{(j)}{ }^{(a)}, \mu_{(j)}{ }^{(b)} \sigma_{(j)}{ }^{(a)}$ and $\sigma(j)^{(b)}=$ Parameterof the joint distribution

This be able to articulated into the compacted variety as: $F\left(a_{i,}, b_{i}\right)$

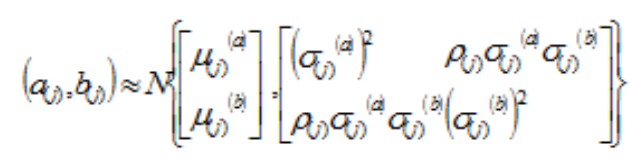

\section{Estimated explanation method:}

Structure of optimal bid strategies used for each hour of the sequence. Subsequent to with the purpose of established of the division status of power producers (GENCOs) to facilitate content unit obligation constraint. The power producer is estimate the trading coefficient basis on PDF. To representation of the uncertainties within the rival activities.

The PDF function used to find large consumers bid coefficients. This makes it stochastic to optimize the probability density (PD) and the equation (10) and (11) so as to subjected to equation (1) and (5). This is solved using the method of optimization. We use PSO \& APSO to solve this stochastic problem.

\section{VI (a). PSO Optimization Technique}

Optimization techniques that work on the theoretical guidelines of the flying birds and fish -school are helpful in solving non-linear and random problems are called as Particle Swarm Optimization (PSO). It was used by social psychologists James Kennedy and Russell Eberhart and solved the optimization problem in 1955. In the optimization technique, the result obtained from the position is called the particle which does get the optimal location to achieve the best result in the $\mathrm{N}$ - dimensions. There is some simple resemblance to computing technologies such as initialization of existing trade. At PSO initialization, a collection of a arbitrary solution is first use in addition to the particle weight modernize is then use to search in support of optimal solutions. This point adjust its flying according near its own flying knowledge in addition to the flying experience of in the neighborhood of particles in problems space.

$$
\begin{gathered}
V_{r}^{K+1}=W^{K} * V_{r}^{K}+C_{1} * \operatorname{rand}_{1} *\left(P_{\text {best }}^{K}-X_{r}^{K}\right)+C_{2} \\
\quad * \operatorname{rand}_{2} *\left(G_{b e s t}^{K}-X_{r}^{K}\right)
\end{gathered}
$$

$\mathrm{E}$

ach particle work in the $\mathrm{N}$ - dimension area behaves like a point and it flying progresses, assuming the experience of self and the rivals in breathing space. The modified velocity of every one particle is calculated by taking the old velocity values $\left(\mathrm{V}_{\mathrm{r}}, \mathrm{K}\right)$ of each particle velocity and each particle iterations given in equation no. (16). Location of Particle where best fitness $\left(P_{\text {Best }}, k\right)$ to be calculated is made by considering best particle fitness of neighbors $\left(G_{\text {Best, }}, k\right)$. $C_{1}$ and $C_{2}$ are learning factors acceleration constant, involve in changing velocity of particle according to best fitness $\left(P_{\text {Best }}, k\right)$ and $\left(G_{\text {Best, }} k\right)$. Random numbers $\mathrm{rad}_{1}$ and $\mathrm{rad}_{2}$ are uniformly distributed in interval $[0,1]$.The equation no.(17) is used to update the position of solution space.

$\mathrm{W}_{\mathrm{k}}$ are weight at $\mathrm{k}^{\text {th }}$ iterations. $\left(P_{\text {Best }}, k\right)$ and $\left(G_{\text {Best }} k\right)$. are optimum particle strength during $\mathrm{K}^{\mathrm{th}}$ iterations of self and rivals particle iterations. $X_{r}^{K+1}$ are newly particle locations. $W_{\text {Max }}$ and $W_{\text {Min }}$ are maximum and minimum weights and $K$ is isolation.

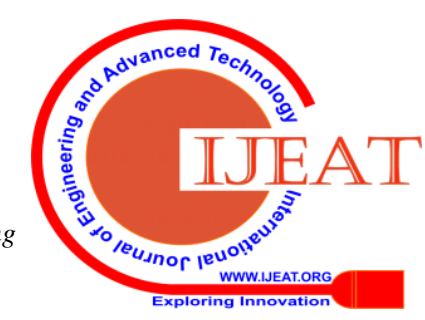


The speed updation equation no.(16) and all three terms involve in speed updates. Particles are move in same dimension until they find fist results and contains inertia. When first particle does not take part in speed updation then particle velocity found from current position and best position in history. Therefore, first term is taking a very important role for finding optimal solution. Recollection and association are take place second and third term respectively. These three terms seek out to unite the particles in the investigation procedure $\left(P_{\text {Best }}, k\right)$ and $\left(G_{\text {Best }}, k\right)$.

\section{Solution procedure of PSO Bidding Problem algorithm}

It has been observed that $\left(a_{i}, b_{i}\right)$ and $\left(c_{j}, d_{j}\right)$ cannot be preferred separately for the maximum benefit of both the efficient supplier (producer) and the buyer (consumer). In this paper, PSO have used for the optimal bidding coefficient for the profit of each participants. The algorithms are given bellow as PSO is used for both purposes [7].

\section{PSO for obtain optimal biddings coefficients $\left(b_{i} / d_{j}\right)$.}

Step(1). In PSO initialization of the swarm particles.

(a) Activate the bi-solution population random within this type of matrix. Which has a bidding parameter $b_{i}$ for configuring the $\mathrm{i}^{\text {th }}$ supplie (generators).

(b) After reading the data of input $\mu, \beta, a_{i}$ and maximum iterative results are find. Where as $\mu, \sigma$ and $\rho$ are respectively mean, standard deviation and coefficient of probability density function(PDF) and $a_{i}$ is known as coefficient of generators.

Step (2). Evaluate the fitness valuation functions for every entity of $b_{i}$,in the equation (14). At this point from probability density function ( PDF) find Fitness valuation.

Step (3). Now compare on each $P_{\text {Best }}$ in all population with other $P_{\text {Best }}$ and replaced by $G_{\text {Best. }}$.

Step (4). At this instant from equation (16) updating in velocity $\mathrm{V}$ by each individual coefficient $b_{\mathrm{i}}$.

Step (5). Now updating the position from position equation (17) by each individual coefficient $\mathrm{b}_{\mathrm{i}}$.

Step(6). Now reiterate the step from 2-5 till reach their highest count. Find optimum value of $b_{i}$ as global solution. Then calculate MCP from equation (7).

2. Profit maximization of generator (supplier) side bidding by using PSO optimization technique.

Step(1). Initiate from particle initialization.

(a). Initialize power population $\mathrm{Pi}$ with arbitrary solution where $\mathrm{Pi}$ is power supplied by ith supplier.

(b). Interpret the supplier data ( i.e. price coefficient, demand (Q0), PMax and PMin) and maximization of iteration number.

Step(2). Compute the fitness valuation using equation (11) $\&(12)$.

Step(3). On comparing each PBest value in population, estimate them PBest and replaced by GBest..

Step(4). At this instant from equation (16) updating in velocity $\mathrm{V}$ by each individual coefficient $\mathrm{Pi}$.

Step (5). Now updating the position from position equation (17) by each individual coefficient $\mathrm{Pi}$.
Step(6). Now reiterate the step from 3-5 till reach their highest count. Find optimum value of power as global solution.

PSO is using in random initialization but this provide approximately same best possible solution within a certain set of solution. Inertia weight approaches (IWA) used for update of PSO subsequent to every iteration.

\section{B. Solution method with Adaptive PSO (APSO)}

That is the additional modification to the standard PSO. In all methods of optimization, APSO [13] is slight advancement towards optimal solutions simply learn from the surrounding particles. In predictable PSO algorithms, non- optimum particles appear to travel near the $\mathrm{G}_{\text {Best }}$ spot. The global best particle drive, therefore discover novel areas and revise the Gbest so as to promote the search for other particles. An adaptive PSO algorithm is proposed within this optimization technique to improve its efficiency (Shaari et al., 2019). In this approach unlike particles are allocate connecting for special tasks. As with traditional PSO, we describe weight from maximum and minimum weight.

However, we can be different weight in this technique by particle performance otherwise task. The particles through advanced performance enclose better inertia weight and responsible for the quest for higher area. Poor-performing particles are given a lesser inertia that helps them to converge rapidly into a better area for thorough search. A higher inertia weight is responsible for a global search whereas a low inertia weight responsible for a local search by the difference in weight. The particles are grouped starting the best to the worst in order of their optimum individual position. The formula for weight updating for APSO is listed below. The update formula is also defined below for this technique and acceleration constant update after each iteration.

$$
\begin{aligned}
& W_{i}=W_{\text {Min }}+\left(W_{\text {Max }}-W_{\text {Min }}\right) *\left\{\frac{m-i}{m-1}\right\} \\
& C_{i 1}=C_{i 2}=\left\{W_{i+1}+2 *\left(W_{i}\right)^{\frac{1}{2}}\right\} / 2
\end{aligned}
$$

Where $\mathrm{m}$ is known as population in the above equation, the inertia weight $\mathrm{W}_{\mathrm{i}}$ shall be modified as stated above. This technique can be used to search both globally and locally in every iteration stage. Velocity and position of APSO will be adjusted the identical as for PSO, however weight and acceleration will be adjusted according to equation (19) \& (20)

\section{Steps for solving APSO optimization techniques}

\section{Initially obtain $\left(b_{i} / d_{j}\right)$ as optimal bidding coefficients}

In APSO first five step are identical as PSO and two further steps are given bellow.

Step(6). The weight update for each bi depends on the weight renewal equation (19).

Step(7). The acceleration factor Ci1 and Ci2 is modified for each bi according to the updating factor acceleration equation (20).

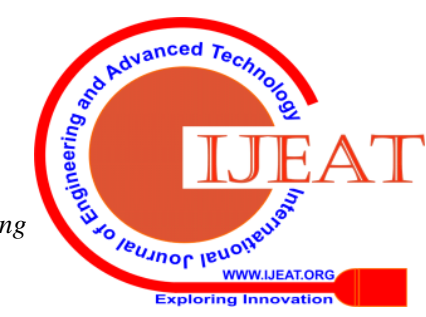


Step(8). Repeat as of steps 3-7 till iteration reaches its maximum count up. Return bi's best value to optimal peak. Eventually iteration as a global fitness . Calculate MCP using the bi values from equati. (7)

To find the optimal dj values, a similar algorithm is applied.

\section{Using APSO to optimize the benefit for supply side bidding.}

The first five steps for APSO will be the same as PSO, and two more steps are written below.

Step(6). Upgrade weight $\mathrm{W}_{\mathrm{i}}$ is according to weight change equation for each one bi (19).

Step(7). According to the acceleration factor update equation (20), update the acceleration factor $\mathrm{C}_{\mathrm{i} 1}$ and $\mathrm{C}_{\mathrm{i} 2}$ for every each individual bi.

Step (8). Repeat from steps 3- till iteration reaches its utmost count. Return the optimal fitness profit of power and full proceeds within the defined limit. At the end of the iteration, both values are treated as a global resolution. APSO provides a further global result than PSO, while the weight and acceleration issue is adapted accordingly to equation (19) \& (20) at any iteration. This will look for more suitable solution because some of the particles have different weights at the start and iteration weight is allocated according to results after first iteration. Starting with terrible results quest for better performance.

\section{RESULT AND DISCUSSION}

We have taken into account six generators (suppliers) and two large consumers (buyers). The data pertaining to the generators (suppliers) along with the consumers (buyers) are arranged in table no.1. the data concern to the mathematical coefficient that were used to fix the bidding problem is also arrange as constant no $\left(Q_{0}\right)$ is 300 while the coefficient expressing the price fluctuations of the total demand $(\mathrm{K})$ is 5. In our paper, the parameters relevant to PSO/APSO are used after the following parameters taken into consideration, Population size: 60, accelerating factors (for PSO only), $\mathrm{C} 1=\mathrm{C} 2=2.0$, inertia weight $\mathrm{W}$ (Wmax,Wmin): 1.10 to 0.55 , Maximum number of iterations: 160. Simulations are performed by using 2.40, Intel(R) core(TM) i5-3337U Processor, 8GB RAM and MATLAB R2018a version.

Table-I: Generator (GENCOs) data details

\begin{tabular}{|l|l|l|l|l|}
\hline $\begin{array}{l}\text { Generator } \\
\text { No. }\end{array}$ & $e$ & $f$ & $\begin{array}{l}\text { Power } \\
\text { min. } \\
\text { (Mega } \\
\text { Watt) }\end{array}$ & $\begin{array}{l}\text { Power } \\
\text { max. } \\
\text { (Mega } \\
\text { Watt) }\end{array}$ \\
\hline 1 & 6.5 & 0.01225 & 45 & 165 \\
\hline 2 & 5.30 & 0.0535 & 35 & 140 \\
\hline 3 & 4 & 0.1385 & 25 & 100 \\
\hline 4 & 9.85 & 0.02632 & 20 & 130 \\
\hline 5 & 9.5 & 0.076 & 25 & 90 \\
\hline 6 & 9.5 & 0.076 & 25 & 90 \\
\hline
\end{tabular}

Where $e, f, g$ and $h$ denotes cost and demand function coefficients of $i^{\text {th }}$ jth generators.

Power min.(Mega Watt) and Power max. (Mega Watt) are generator limits.

Table-II: Consumer (DISCOMs) data details

\begin{tabular}{|l|l|l|l|l|}
\hline $\begin{array}{l}\text { Large } \\
\text { consumer } \\
\text { (buyers) }\end{array}$ & $\boldsymbol{g}$ & $\boldsymbol{h}$ & $\begin{array}{l}\text { Demand } \\
\text { min.(Mega } \\
\text { Watt) }\end{array}$ & $\begin{array}{l}\text { Demand } \\
\text { max.(Mega } \\
\text { Watt) }\end{array}$ \\
\hline 1. & 32 & 0.05 & 0 & 190 \\
\hline 2. & 24 & 0.02 & 0 & 145 \\
\hline
\end{tabular}

Demand min.(Mega Watt) and Demand max.(Mega Watt) are demand limits

\section{With Symmetrical Information}

Two bidding cases are considerable, first case deal all the same information of all participants depend on bidding history. Where as in second case compare to each other. In this paper we consider all six generator (GENCOs) and two large consumers (DISCOs) taking case of category fist with same estimation and information.Each rival participants are assumed to contain an estimation joint as normal distribution on behalf of the two bidding coefficient. In this particular problems joint normal distribution constraint are taken as PDF equation are given in (14) are described as.

$$
\begin{aligned}
& \mu_{i}(\mathrm{a})=1.2 \times\left(\mathrm{e}_{\mathrm{i}}\right) \quad \mu_{\mathrm{i}}(\mathrm{b})=1.2 \times 2\left(\mathrm{f}_{\mathrm{i}}\right) \\
& \mu_{\mathrm{i}}(\mathrm{a})=1.2 \times\left(\mathrm{e}_{\mathrm{i}}\right) \quad \mu_{\mathrm{i}}(\mathrm{b})=1.2 \times 2\left(\mathrm{f}_{\mathrm{i}}\right) \\
& 4 \times \sigma_{\mathrm{i}}(\mathrm{a})=0.15 \times \mathrm{e}_{\mathrm{i}}, 4 \times \sigma_{\mathrm{i}}(\mathrm{b})=0.15 \times \mathrm{f}_{\mathrm{i}} \quad \mathrm{Bi}_{\mathrm{i}}=-0.1(21) \\
& \mu_{\mathrm{j}}(\mathrm{c})=1.2 \times\left(\mathrm{g}_{\mathrm{i}}\right), \quad \mu_{\mathrm{j}}(\mathrm{d})=1.2 \times 2\left(\mathrm{~h}_{\mathrm{i}}\right) \\
& 4 \times \sigma_{\mathrm{j}}(\mathrm{c})=0.15 \times \mathrm{e}_{\mathrm{j}} \\
& \gamma_{\mathrm{j}}=0.1
\end{aligned}
$$

Where $\rho \mathbf{i}=$ Correlation coeffi. between aj and bj. Standard deviation $\sigma \mathrm{j}(\mathrm{a})$ and $\sigma \mathrm{j}(\mathrm{b})$.

$\mu \mathrm{j}(\mathrm{c})$ and $\mu \mathrm{j}(\mathrm{d})=$ Constraint of joint normal distribution s of mean value

$\sigma \mathrm{i}(\mathrm{a})$ and $\sigma \mathrm{i}(\mathrm{b})=$ Constraints of joint normal distribution's standard deviation

Equations (21) and (22) must be solved by using mathematical assumption also these equations are used previous bidding data history. It is a showing basic feature of these methods and not reflected the practical behaviour and taking reasonable assumptions about generator (GENCOs) equations. Therefore they want increase its profit by using bidding method above the marginal (production) cost by taking estimated values of mean values $\left(\mathrm{a}_{\mathrm{i}}\right.$ and $\left.\mathrm{b}_{\mathrm{i}}\right)$. Mean values $\mu_{j}(c)$ and $\mu_{j}(d)$ are specified $20 \%$ higher than $e_{i}$ and $2\left(f_{i}\right)$. Standard deviation $\left(\sigma_{j}(a)\right.$ and $\sigma_{j}(b)$ coefficients $a_{i}$ and $b_{i}$ are fall in the specified range $\left[1.05 * e_{i}, 1.35 * e_{i}\right.$ ] with probability of $0.999 . \rho_{i}$ is specific toward negative since it shows inverse relation bidding coefficients such that when generator(GENCOs) increase its bidding coefficients more likely other coefficient will decrease as same instant. The parameters in equation (22) are applicable as in equation (21).

In this paper bidding coefficient of generators (GENCOs) and consumer (DISCOMs) profit and market clearing price (MCP) are calculated. Six generators(GENCOs) and two buyers (DISCOMs) are consider for PSO optimization techniques and similar problem solved by using APSO and compared to each other as well as given in table 3 .
Published By:

Blue Eyes Intelligence Engineering \& Sciences Publication

(C) Copyright: All rights reserved.

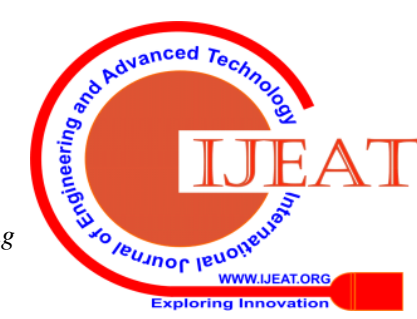


Table-III: Bidding Strategies of Supplier (GENCOs) and Consumers (DISCOMs) details

\begin{tabular}{|c|c|c|}
\hline & PSO & APSO \\
\hline Generators(GENCOs) & $\begin{array}{l}\text { Bidding } \\
\text { Coefficients } \\
\left(\mathrm{b}_{\mathrm{i}}\right)\end{array}$ & $\begin{array}{l}\text { Bidding } \\
\text { Coefficients } \\
\left(\mathrm{b}_{\mathrm{i}}\right)\end{array}$ \\
\hline 1 & 0.056 & 0.079 \\
\hline 2 & 0.067 & 0.078 \\
\hline 3 & 0.235 & 0.256 \\
\hline 4 & 0.052 & 0.054 \\
\hline 5 & 0.103 & 0.163 \\
\hline 6 & 0.124 & 0.164 \\
\hline $\begin{array}{l}\text { Consumer } \\
\text { (DISCOMs) }\end{array}$ & $\begin{array}{l}\text { Bidding } \\
\text { Coefficients } \\
\left(\mathrm{d}_{\mathrm{j}}\right)\end{array}$ & $\begin{array}{l}\text { Bidding } \\
\text { Coefficients } \\
\left(d_{j}\right)\end{array}$ \\
\hline 1 & 0.081 & 0.084 \\
\hline 2 & 0.052 & 0.054 \\
\hline
\end{tabular}

In these tables shows optimal bidding coefficient in table 2 and table 3 shows profit and market clearing pricing (MCP) of each one generator (GENCOs) and consumer (DISCOMs).

Table-IV: Bidding Price(\$/MWh) and Profit of Generators (GENCOs) and Consumers (DISCOMs) details

\begin{tabular}{|l|l|l|l|l|}
\hline & \multicolumn{3}{|l|}{ PSO } & \multicolumn{2}{l|}{ APSO } \\
\hline $\begin{array}{l}\text { Generators(GE } \\
\text { NCOs) }\end{array}$ & $\begin{array}{l}\text { Power } \\
\text { (Mega } \\
\text { Watt) }\end{array}$ & $\begin{array}{l}\text { Profi } \\
\text { (\$) }\end{array}$ & $\begin{array}{l}\text { Power } \\
\text { (Mega } \\
\text { Watt) }\end{array}$ & $\begin{array}{l}\text { Prof } \\
\text { it } \\
(\$)\end{array}$ \\
\hline 1 & 156.68 & $\begin{array}{l}1251 \\
.54\end{array}$ & 138.45 & $\begin{array}{l}142 \\
7.46\end{array}$ \\
\hline 2 & 108.54 & $\begin{array}{l}485 . \\
65\end{array}$ & 96.87 & $\begin{array}{l}503 . \\
36\end{array}$ \\
\hline 3 & 42.67 & $\begin{array}{l}256 . \\
47\end{array}$ & 42.65 & $\begin{array}{l}283 . \\
47\end{array}$ \\
\hline 4 & 109.85 & $\begin{array}{l}439 . \\
86\end{array}$ & 106.47 & $\begin{array}{l}472 . \\
45\end{array}$ \\
\hline 5 & 52.64 & $\begin{array}{l}146 . \\
26\end{array}$ & 47.36 & $\begin{array}{l}253 . \\
74\end{array}$ \\
\hline 6 & 52.63 & $\begin{array}{l}145 . \\
69\end{array}$ & 47.38 & $\begin{array}{l}253 . \\
87\end{array}$ \\
\hline $\begin{array}{l}\text { Consumer } \\
\text { (DISCOMs) }\end{array}$ & & & & \\
\hline 1 & 156.87 & $\begin{array}{l}1256 \\
.57\end{array}$ & 163.47 & $\begin{array}{l}139 \\
6.43\end{array}$ \\
\hline 2 & 139.47 & 664. & 142.64 & $\begin{array}{l}782 . \\
68\end{array}$ \\
\hline $\begin{array}{l}\text { Total(net) } \\
\text { Profit }\end{array}$ & 14.89 & 35 & & 16.79 \\
\hline
\end{tabular}

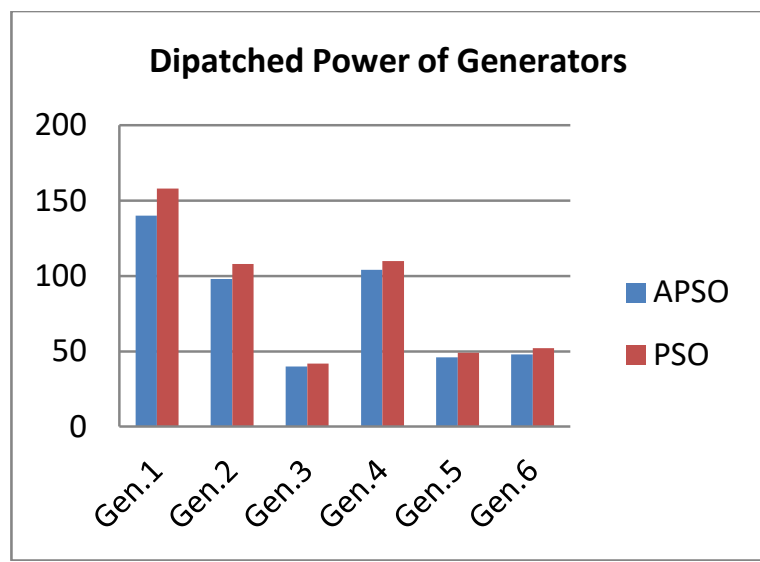

Fig.1. Expected dispatched powers of generators (GENCOs)

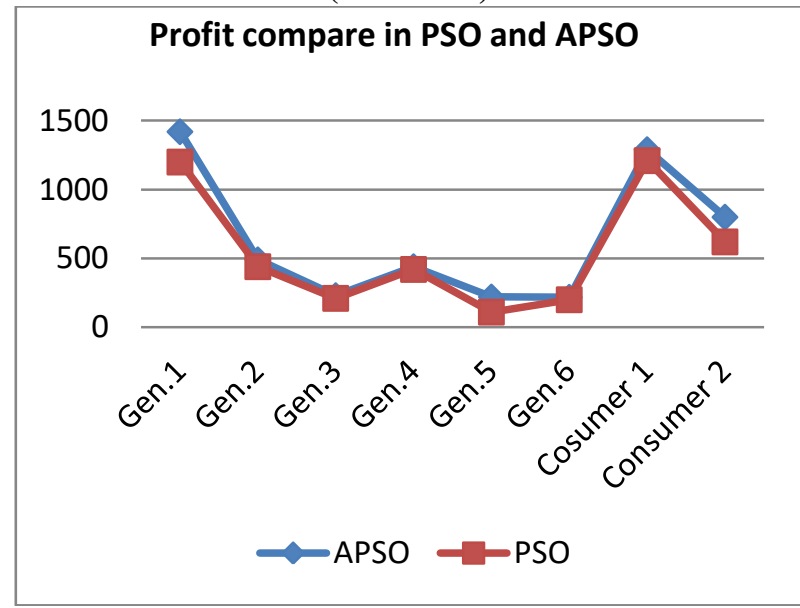

Fig..2. Expected profits of participant of suppliers (GENCOs) and consumers (DISCOMs)

It is cleared from tables and figures that the profit (\$) obtained by each generator (GENCOs) is on comparing better than with PSO. The mainly difference between APSO and PSO that the performance and weight are updating after each one iteration considering weight and acceleration factor taken into account which leading to optimal solution. The APSO is more proficient optimization techniques than PSO which is shows by simulating results. These optimization techniques are working on random initialization principle. In this paper, there are not grant a optimal result in single run on MATLAB code. I found optimal result by numerous trails through different initialization as well as attain a valid conclusion based on concert of the algorithms. Since random nature of PSO and APSO all approaches of bidding data executed 20 times. At this situation bidding data executed more than 20 times for find the appropriate optimal solution.

\section{CONCLUSION}

This paper present a estimation for two optimization strategies on random bidding problem using particle swam optimization (PSO) and adaptive PSO (APSO). Through these strategies participants want to increase their benefit on the competition of electricity market through the use of market operator details. Here we discuss the symmetrical information of the electricity rivals who use information like APSO and PSO in the random nature of the information with other optimization techniques,

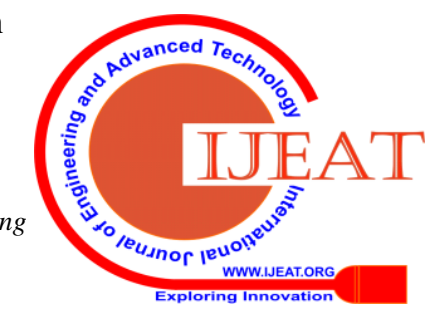




\section{Cost-Effective Electric Energy Bidding Strategies Applying with Particles Swarm Optimization and Adaptive Particle Swarm Optimization}

the advantage of APSO and PSO is that these are able to control and congregate the bidding data efficiently. On the other hand adaptive PSO (APSO) provides as better alternative than PSO.

\section{REFERENCES}

1. Weron R, "Electricity price forecasting: A review of the state-of-theart with a look into the future," International journal of forecasting. 2014 Oct 1;30(4):1030-81.

2. Banshwar A, Sharma NK, Sood YR, Shrivastava R, "Real time procurement of energy and operating reserve from Renewable Energy Sources in deregulated environment considering imbalance penalties,' Renewable Energy. 2017 Dec 1;113:855-66.

3. Kavtaradze L, Mokhtari M, "Factor Models and Time-Varying Parameter Framework for Forecasting Exchange Rates and Inflation,' A Survey. Journal of Economic Surveys. 2018 Apr;32(2):302-34.

4. Chinmoy L, Iniyan S, Goic R., “ Modeling wind power investments, policies and social benefits for deregulated electricity market-A review," Applied energy. 2019 May 15;242: 364-77.

5. Hullova D, Laczko P, Frishammar J, "Independent distributors in servitization: An assessment of key internal and ecosystem-related problems," Journal of Business Research. 2019 Nov 1;104:422-37.

6. Coester A, Hofkes MW, Papyrakis E, "An optimal mix of conventional power systems in the presence of renewable energy: A new design for the German electricity market," Energy Policy. 2018 May 1;116:312-22.

7. Lanxiang J, Honglei W, Zhijun H, Wei Z. Repeated game analysis of power suppliers based on dynamic coopetition process and slightly altruistic factor. Cluster Computing. 2019 Mar 1;22(2):4075-84.

8. Yang J, Zhao J, Qiu J, Wen F, “A Distribution Market Clearing Mechanism for Renewable Generation Units With Zero Marginal Cost,." IEEE Transactions on Industrial Informatics. 2019 Jan 30;15(8):4775-87.

9. Shafie-Khah, M., et al, "Optimal trading of plug-in electric vehicle aggregation agents in a market environment for sustainability," Applied Energy 162 (2016): 601-612.

10. Jiang Y, Hou J, Lin Z, Wen F, Li J, He C, Ji C, Lin Z, Ding Y, Yang L. Optimal bidding strategy for a power producer under monthly prelisting balancing mechanism in actual sequential energy dual-market in China. IEEE Access. 2019 May 27;7:70986-98.

11. Rahman I, Mohamad-Saleh J. Hybrid bio-Inspired computational intelligence techniques for solving power system optimization problems: A comprehensive survey. Applied Soft Computing. 2018 Aug 1;69:72-130.

12. Kester J, Noel L, de Rubens GZ, Sovacool BK. Promoting Vehicle to Grid (V2G) in the Nordic region: Expert advice on policy mechanisms for accelerated diffusion. Energy Policy. 2018 May 1;116:422-32.

13. Jordehi AR. Optimisation of demand response in electric power systems, a review. Renewable and Sustainable Energy Reviews. 2019 Apr 1;103:308-19.

14. Zaman F, Elsayed SM, Ray T, Sarker RA. Co-evolutionary approach for strategic bidding in competitive electricity markets. Applied Sof Computing. 2017 Feb 1;51:1-22.

15. Agrawal A, Kumar A, Rao TJ. Future of Indian power sector reforms: electricity amendment bill 2014. Energy Policy. 2017 Aug 1;107:491-7.

16. Chever L, Saussier S, Yvrande-Billon A. The law of small numbers: Investigating the benefits of restricted auctions for public procurement. Applied Economics. 2017 Sep 8;49(42):4241-60.

17. Van Ackooij W, Lopez ID, Frangioni A, Lacalandra F, Tahanan M. Large-scale unit commitment under uncertainty: an updated literature survey. Annals of Operations Research. 2018 Dec 1;271(1):11-85.

18. Banshwar A, Sharma NK, Sood YR, Shrivastava R. An international experience of technical and economic aspects of ancillary services in deregulated power industry: Lessons for emerging BRIC electricity markets. Renewable and Sustainable Energy Reviews. 2018 Jul 1;90:774-801.

19. Singh S, Fozdar M. Double-sided bidding strategy for power suppliers and large buyers with amalgamation of wind and solar based generation in a modern energy market. IET Generation, Transmission \& Distribution. 2019 Nov 26;14(6):1031-41.

20. Nguyen DH, Narikiyo T, Kawanishi M. Optimal demand response and real-time pricing by a sequential distributed consensus-based ADMM approach. IEEE Transactions on Smart Grid. 2017 Mar 1;9(5):4964-74.

21. Moreno-Munoz A, Bellido-Outeirino FJ, Siano P, Gomez-Nieto MA. Mobile social media for smart grids customer engagement: Emerging

Published By:

Blue Eyes Intelligence Engineering \& Sciences Publication

trends and challenges. Renewable and Sustainable Energy Reviews. 2016 Jan 1;53:1611-6.

22. Bradley S. Inattention to deferred increases in tax bases: How Michigan home buyers are paying for assessment limits. Review of Economics and Statistics. 2017 Mar 1;99(1):53-66.

23. Mukherjee S, Dhingra T, Sengupta A. Status of Electricity Act, 2003: A systematic review of literature. Energy Policy. 2017 Mar $1 ; 102: 237-48$

24. Märkle-Huß J, Feuerriegel S, Neumann D. Contract durations in the electricity market: Causal impact of 15 min trading on the EPEX SPOT market. Energy Economics. 2018 Jan 1;69:367-78.

25. Sauhats A, Zemite L, Petrichenko L, Moshkin I, Jasevics A Estimating the economic impacts of net metering schemes for residential PV systems with profiling of power demand, generation, and market prices. Energies. 2018 Nov;11(11):3222.

26. Prabavathi M, Gnanadass R. Bidding strategies for Indian restructured power market. In2013 International Technologies (ICCPCT) 2013 Mar 20 (pp. 568-573). IEEE

27. Banshwar A, Sharma NK, Sood YR, Shrivastava R. An internationa experience of technical and economic aspects of ancillary services in deregulated power industry: Lessons for emerging BRIC electricity markets. Renewable and Sustainable Energy Reviews. $2018 \mathrm{Ju}$ 1;90:774-801

\section{AUTHORS PROFILE}

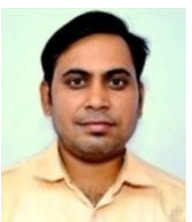

Pramesh Kumar received his M.Tech and B.Tech degree from Maulana Azad National Institute of Technology Bhopal (M.P.) and Institute of Engineering and Technology MJPRU Bareilly (U.P.) India, in 2010 and 2008 respectively. Presently he is research scholar from Maulana Azad National Institute of Technology Bhopal M.P. India. His main area of research includes Electricity marketing, power system economics, electricity pricing, deregulation, optimization techniques.

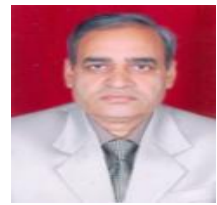

Dr. S. K. Bharadwaj received his Ph.D., M.sc and B.Tech degrees in electrical engineering in 1975,1978 and 1992 respectively. He is working as a professor in electrical engineering department MANIT Bhopal M.P., India. He published more than 25 Paper in International Journals, 60 Paper in the National Level Conference and 20 Paper in International Level Conference. Membership in IEEE, International Association of Computer Science and Information Technology (IACSIT), Computer Science Teachers Association (CSTA), International Association of Engineers (IAENG),International Webmasters Association (IWA). His main area of research includes power system economics, deregulation of electricity, control technology and renewable energy sources 